(C) 2021 The Authors. Cognitive Science published by Wiley Periodicals LLC on behalf of Cognitive Science Society (CSS).

\title{
Are There Cross-Cultural Legal Principles? Modal Reasoning Uncovers Procedural Constraints on Law
}

\author{
Ivar R. Hannikainen, ${ }^{\mathrm{a}}$ Kevin P. Tobia, ${ }^{\mathrm{b}}$ Guilherme da F. C. F. de Almeida, ${ }^{\mathrm{c}}$ \\ Raff Donelson, ${ }^{\mathrm{d}}$ Vilius Dranseika, ${ }^{\mathrm{e}}$ Markus Kneer, ${ }^{\mathrm{f}}$ Niek Strohmaier, ${ }^{\mathrm{g}}$ \\ Piotr Bystranowski, ${ }^{\mathrm{e}}$ Kristina Dolinina, ${ }^{\mathrm{h}}$ Bartosz Janik, ${ }^{\mathrm{i}}$ Sothie Keo ${ }^{\mathrm{j}}$
} Egle Lauraitytè, ${ }^{\text {h }}$ Alice Liefgreen, ${ }^{\mathrm{k}}$ Maciej Próchnicki, ${ }^{\mathrm{e}}$ Alejandro Rosas, Noel Struchiner ${ }^{\mathrm{c}}$

\author{
${ }^{a}$ University of Granada, Spain \\ ${ }^{\mathrm{b}}$ Georgetown University, USA \\ ${ }^{\mathrm{c}}$ Pontifical Catholic University of Rio de Janeiro, Brazil \\ ${ }^{\mathrm{d}}$ Pennsylvania State University, USA \\ e Jagellonian University, Poland \\ ${ }^{\mathrm{f}}$ University of Zurich, Switzerland \\ ${ }^{\mathrm{g}}$ Leiden University, The Netherlands \\ ${ }^{\mathrm{h}}$ Vilnius University, Lithuania \\ ${ }^{\mathrm{i}}$ University of Silesia, Poland \\ ${ }^{\mathrm{j}}$ American University of Phnom Penh, Cambodia \\ ${ }^{\mathrm{k}}$ University College London, $U K$ \\ ${ }^{1}$ National University of Colombia at Bogotá, Colombia
}

Received 20 November 2020; received in revised form 28 June 2021; accepted 29 June 2021

\begin{abstract}
Despite pervasive variation in the content of laws, legal theorists and anthropologists have argued that laws share certain abstract features and even speculated that law may be a human universal. In the present report, we evaluate this thesis through an experiment administered in 11 different countries. Are there cross-cultural principles of law? In a between-subjects design, participants $(N=3,054)$ were asked whether there could be laws that violate certain procedural principles (e.g., laws applied
\end{abstract}

Correspondence should be sent to Ivar R. Hannikainen, Department of Philosophy I, Faculty of Psychology, Cartuja Campus, Universidad de Granada, Granada 18011, Spain. E-mail: ivar@ugr.es

This is an open access article under the terms of the Creative Commons Attribution-NonCommercial-NoDerivs License, which permits use and distribution in any medium, provided the original work is properly cited, the use is non-commercial and no modifications or adaptations are made. 
retrospectively or unintelligible laws), and also whether there are any such laws. Confirming our preregistered prediction, people reported that such laws cannot exist, but also (paradoxically) that there are such laws. These results document cross-culturally and -linguistically robust beliefs about the concept of law which defy people's grasp of how legal systems function in practice.

Keywords: Concepts; Experimental jurisprudence; Human universals; Lon Fuller; Modality; Natural law

\section{Introduction}

Laws vary remarkably from one jurisdiction to the next. Even within jurisdictions, legislative changes are frequent and shift the legal status of various practices over time. These changes in legality accompany fluctuations in the prevailing morality (Ofosu, Chambers, Chen, \& Hehman, 2019), perhaps even helping to precipitate shifts in public opinion. Despite the abrupt historical change and cultural diversity in the content of legal norms, theorists in law (Finnis, 1980; Fuller, 1964) and anthropology (Brown, 1991) have speculated that certain features of their form may be universal. Yet, no research to date has examined whether people across cultures share intuitions about what laws fundamentally are. In the present work, we sought to fill this gap in our understanding of the cognitive science of law.

In the neighboring disciplines of moral psychology and behavioral economics, extensive research agendas have now documented robust patterns in people's moral (Cushman, Young, \& Hauser, 2006; Rozin, Lowery, Imada, \& Haidt, 1999) and economic (Boyer \& Pedersen, 2018) preferences across various cultures (Hannikainen et al., 2019). These research programs have uncovered various universal ethical principles, for instance, the role of intent in moral blameworthiness (Barrett et al., 2016), the distinction between personal and impersonal forms of harm (Awad, Dsouza, Shariff, Rahwan, \& Bonnefon, 2020), the tendency to uphold taboos related to bodily purity and sanctity (Graham, Haidt, \& Nosek, 2009), such as norms proscribing sibling incest (Haidt, Koller, \& Dias, 1993), and systematic deviations from self-interest, such as the tendency to exact costly punishment (Henrich et al., 2005).

Theorists in the legal domain have argued that this palette of moral sentiments forms the basis for an "intuitive jurisprudence" (Mikhail, 2007; Sznycer \& Patrick, 2020), according to which the structure and content of criminal legal codes crystallize basic aspects of our moral sense. In one recent study (Sznycer \& Patrick, 2020), participants were asked to consider a series of ancient laws, drawn from the Tang Code (such as gratuitously killing one's slave) and the Laws of Eshnunna (such as liability for one's goring ox), and reported their moral reactions - for example, of perceived shame and wrongness - in response to hypothetical violations of these dated laws. Strikingly, the intensity of participants' reactions predicted the magnitude of legal punishment, whether in the form of a fine or prison time, stipulated in these millennia-old criminal codes. This universalist paradigm-implicating our basic moral sensibilities in the genesis of legal doctrines-would also help explain the near-universal emergence of certain criminal laws (e.g., regarding murder, see Mikhail, 2009) and of legal institutions as a basic property of social groups (Brown, 1991; Hoebel, 1954; Nader, 1965). 
In our present study, we pursue a related prediction: namely, that people around the world share an intuitive grasp of the formal properties of law-as well as its content. The view that laws must observe certain procedural principles has come to be associated most strongly with the work of American philosopher Lon Fuller. His famous (1964) book told the tale of a hypothetical king, Rex, who- through a sequence of failures — gradually discovered the eight procedural principles capable of transforming his imperatives and royal wishes into what could be properly referred to as a legal system. For instance, at first, Rex did not publicly proclaim the rules of his kingdom, but instead kept them secret in his diary. As a result, the populace could not possibly know Rex's rules-which taught Rex his first lesson: that laws need to be publicly promulgated.

Philosophers of law have recurrently debated the question of whether laws must meet certain procedural requirements, but the corresponding body of empirical evidence examining whether the concept of law exhibits such constraints is meager. One recent study - which inspired the present attempt at cross-cultural generalization-did reveal that lawyers and laypeople in the United States consider the procedural principles illustrated in Fuller's (1964) writings to be, in a paradoxical sense, essential to the law (Donelson \& Hannikainen, 2020).

The paradox lies in the way participants reacted to different linguistic formulations of the same procedural principles:

One group of participants was asked to assess whether, in their experience, laws observe or violate each of the procedural principles (e.g., whether or not there are laws "punishing people for acts that were legal at the time they were performed"). Looking across all eight procedural principles, participants were divided on whether actual laws abide by these procedural principles.

According to most systems of modal logic, if there exists even a single retrospective law, it follows that retrospective laws certainly could exist-in virtue of axiom $M$. A separate group of participants were asked precisely this question: Could the laws of a hypothetical nation violate each of the procedural principles (e.g., whether there could be any laws "punishing people for acts that were legal at the time they were performed")? Both lawyers and nonlawyers reported the opposite pattern of responses: namely, that there could not be any retrospective laws (even though there actually are). A very similar pattern emerged when considering the remaining procedural principles: for example, that laws be announced publicly, made intelligible to the vast majority, changed infrequently at most, and so on.

Did this effect arise simply because participants did not grasp the relevant axiom of modal logic (i.e., that if a law exhibits property $P$, then laws necessarily could exhibit property $P$ )? A follow-up study spoke against this explanation: When asked to simultaneously consider actual and possible laws, participants reported that laws often abide by the procedural principles, though it would be possible for laws to violate them-reversing the direction of the difference between conditions.

In sum, this preliminary evidence reveals an apparent contradiction: that laws need to observe certain procedural constraints, even though actual laws routinely violate them. One question this raises is: If, from their empirical knowledge of what laws are like, people conclude that there are no procedural principles that laws generally abide by; then how might they form the inconsistent judgment that laws could not possibly violate those same principles? 
One possibility is that this judgment stems from a mental representation or concept of "law" (Margolis \& Laurence, 1999). Such a concept could be a prototype, or essentialized belief - arising from the simpler concepts of "norm," "fairness," and "punishment," for example_and which depends weakly on one's experience with actual laws. This hypothesis yields a further empirical prediction: that the tendency to ascribe these procedural properties to law should emerge across cultures, despite fundamental variation in the particularities of each legal system and its manifestation.

To examine this prediction, we sampled from what comparative law scholars describe as the two primary legal systems: that is, common (e.g., United States and India) and civil law (e.g., Brazil and Poland; see Dainow, 1966). The former tradition evolved in England and characteristically places greater weight on judge-made law (i.e., previous judicial decisions and precedential cases); the latter originated in mainland Europe and places greater weight on statutory law (i.e., codified law written by legislators). This distinction, however, is sometimes seen as overly coarse (see Merryman \& Pérez-Perdomo, 2020). Additionally, we ascertained that the 11 jurisdictions in our study varied in the strength of the rule of law (see World Justice Project, 2020).

Finally, we administered the study in the local language for each field site, helping to establish whether the effect of modal reasoning on beliefs about the law arises across different language families (from Romance, Germanic, and Balto-Slavic, to Indic and Austroasiatic families).

This cross-cultural and -linguistic approach enables us to sidestep a widespread limitation of previous research in psychological science: Various reports have highlighted the discipline's ethnocentric bias (e.g., Thalmayer, Toscanelli, \& Arnett, 2021) in advancing claims about human psychology on the basis of evidence derived almost exclusively from Western, English-speaking samples.

\section{Methods}

\subsection{Field sites and participants}

We selected 11 different field sites for data collection on the basis of (i) linguistic and cultural diversity, and (ii) variation in the strength of the rule of law. To ensure a balance of strong and weak rule of law, we consulted the Rule of Law Index 2020 (World Justice Project, 2020). The Rule of Law Index draws on thousands of household and expert surveys worldwide to quantify the strength of the rule of law across nations along eight complementary dimensions: constraints on government, absence of corruption and "revolving doors," open government (guaranteeing information and civic participation), fundamental rights (e.g., absence of discrimination and freedom of expression and assembly), order and security (low levels of crime and political violence), regulatory enforcement, civil justice, and criminal justice. The Netherlands and Germany were rated as having very strong rule of law-appearing among the top 10 countries. Some other countries (including Brazil, India, Colombia, and Cambodia) were classified as having a weak rule of law, and spanned the bottom half of the global ranking. 
Table 1

Sample characteristics

\begin{tabular}{lllll}
\hline Country & $N$ & Age Mean (SD) & Gender (\% women) & Recruitment method \\
\hline Brazil & 223 & $27.5(10.1)$ & $51.0 \%$ & Word-of-mouth \\
Cambodia & 100 & $24.1(6.31)$ & $55.0 \%$ & Word-of-mouth \\
Colombia & 263 & $22.1(3.80)$ & $35.4 \%$ & Extra-credit \\
Germany & 237 & $37.1(11.7)$ & $50.2 \%$ & Panel (www.clickworker.de) \\
India & 275 & $32.7(9.50)$ & $63.3 \%$ & Panel (www.qualtrics.com) \\
Lithuania & 242 & $32.4(9.35)$ & $43.0 \%$ & Word-of-mouth \\
The Netherlands & 722 & $45.9(14.3)$ & $48.9 \%$ & Word-of-mouth \& Panel \\
& & & & (www.panelinzicht.nl) \\
Poland & 271 & $29.2(8.54)$ & $42.3 \%$ & Word-of-mouth \\
Spain & 289 & $43.2(15.3)$ & $55.1 \%$ & Panel (www.netquest.com) \\
United Kingdom & 210 & $35.2(12.7)$ & $62.9 \%$ & Panel (www.prolific.ac) \\
United States & 222 & $37.4(11.4)$ & $57.0 \%$ & Panel (www.mturk.com) \\
ToTAL & 3,054 & $36.0(14.0)$ & $48.5 \%$ & - \\
\hline
\end{tabular}

The minimum target sample size per site was established at 100 participants per condition and field site (i.e., target $n=200 /$ site), and was met everywhere except Cambodia (see Table 1). This sample size provides adequate statistical power $(\beta=.20)$ to detect an odds ratio $\geq 1.40$ setting $\alpha$ at .05 .

\subsection{Materials}

The stimuli were adapted from Donelson and Hannikainen (2020) and translated into eight additional languages by native speakers: Dutch, German, Hindi, Khmer, Lithuanian, Polish, Portuguese, and Spanish. Site collaborators were asked to iteratively compare oral backtranslations (into English) against the original materials.

The main task was made up of eight pairs of statements with an affirmation (e.g., "Some laws change very frequently") and a negation (e.g., "No laws change very frequently") in each pair. These items could be worded as either existential statements, or modal statements as shown in Figure 1.

Thus, the difference between conditions was the inclusion of an auxiliary verb transforming the existential statements into modal statements. In each language, we sought to employ auxiliary verbs that primarily denote possibility and necessity (i.e., alethic modality; see Table 2).

The post-experiment test consisted of three questions, assessing how participants had interpreted the task. On a seven-point scale anchored at -3: "Not at all" and 3: "Completely," reported whether they were thinking about:

1. "what laws are usually like, in your experience" (i.e., empirical interpretation),

2. "what laws have to be like, as in the requirements for something to count as law" (i.e., alethic interpretation)

3. "what laws should be like, according to your beliefs about right and wrong" (i.e., deontic interpretation). 


\section{Actual Possible}

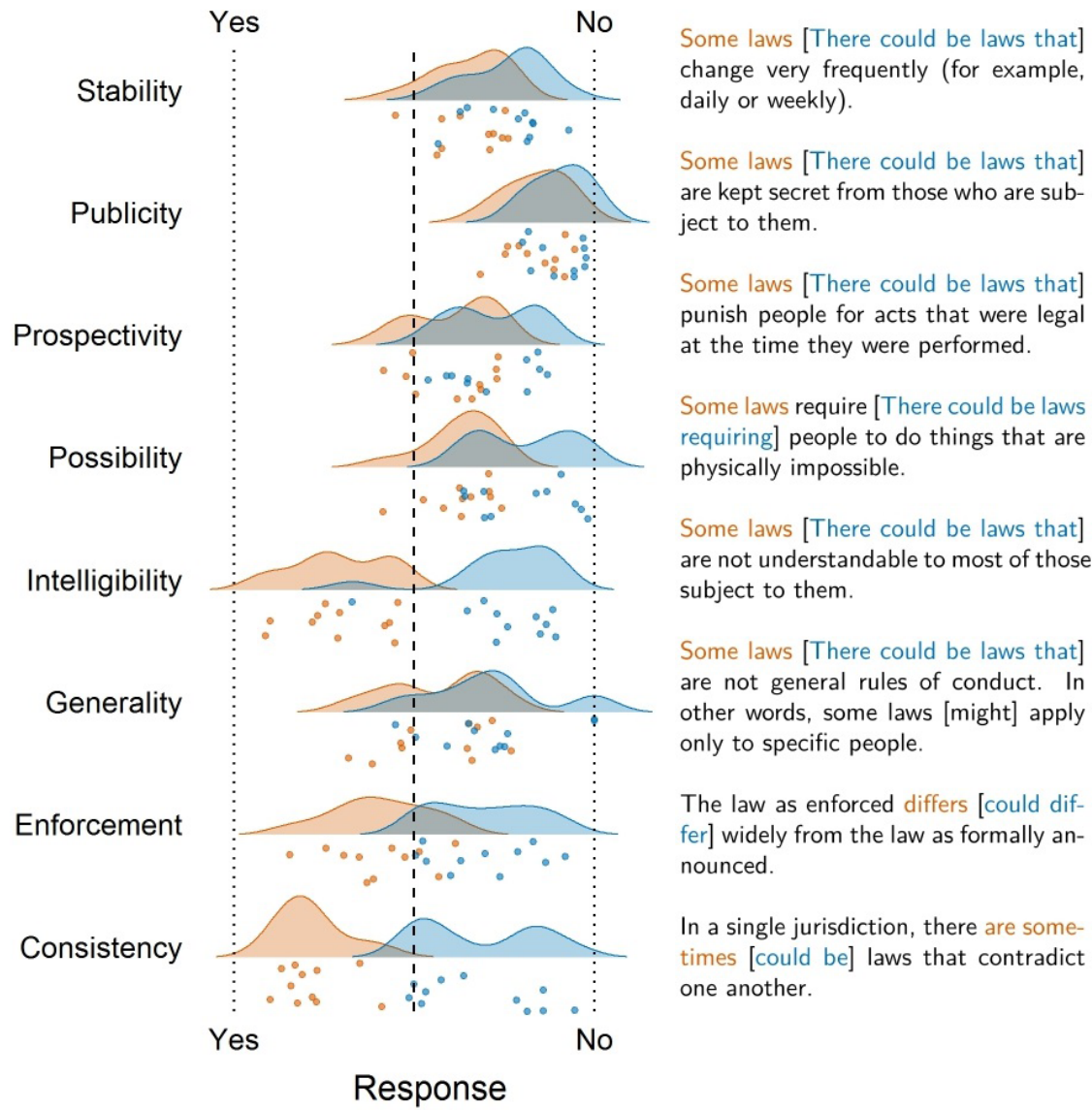

Fig. 1. Rain cloud plot: probability density and scatter plot by procedural principle and condition. Each dot represents a country.

Materials in every language are available on the Open Science Framework at: https://osf. io/hn8m5/.

\subsection{Procedure}

In a between-subjects design, participants were randomly assigned to either the Actual or the Possible condition, and read the following introduction:

You will be shown eight pairs of statements regarding what laws are like. For each pair of statements, please take a moment to think about which statement better reflects your opinion about what laws are like. 
Table 2

Modal auxiliary verbs by language

\begin{tabular}{|c|c|}
\hline Language & auxiliary verb (count) \\
\hline English & could (14), would (4), might (1). \\
\hline Dutch & $\begin{array}{l}\text { kan/zouden kunnen (14), moeten/zouden moeten (3), } \\
\text { mogelijk (1). }\end{array}$ \\
\hline German & könnte/könnten (10), kann (7), können (1). \\
\hline Hindi & सकना (sakanā; 15), होना (honā; 3), चाहिए (cāhiye; 1). \\
\hline Khmer & ราษ $($ ach; 19), ถึน (nung; 4). \\
\hline Lithuanian & (ne)galètų (14), turètų (4), gali (1). \\
\hline Polish & może/mogą (15), muszą (4). \\
\hline Portuguese & poderia/poderiam (14), teria/teriam (3). \\
\hline Spanish & podría/podrían (16), tendría/tendrían (3). \\
\hline
\end{tabular}

In each condition, the statement pairs were presented in a random order across participants. In the Actual condition, participants read an existential statement and its negation in each pair. Meanwhile, in the Possible condition, each pair contained a modal statement employing an auxiliary verb and its negation. Participants were asked to endorse one statement from each pair. On the following page, participants were asked a set of three questions about their interpretation of the task.

Lastly, participants provided demographic information: age (in years), gender (Male, Female, Nonbinary), and legal background (Law student, Legal professional, Neither). Subgroup analyses are reported in Supplementary Analysis 1.

\subsection{Predictions and analysis plan}

Our primary prediction, sample size determination, and analysis plan were preregistered at https://aspredicted.org/zt4jr.pdf. Inspired by previous findings (Donelson \& Hannikainen, 2020), we hypothesized greater endorsement of procedural principles in the Possible condition than in the Actual condition.

We coded endorsement as 1 if participants reported that a principle obtains, for example, selected "The law as enforced does not [/could not] differ from the law as formally announced." Endorsement was coded as 0 if participants stated that a principle was or could be violated, that is, selected "The law as enforced differs [/could differ] from the law as formally announced." In the analyses below, we conducted logistic regression models predicting the probability $\left(p^{\wedge}\right)$ that participants endorse the procedural principle(s).

We tested our primary prediction in a mixed-effects logistic regression model entering experimental condition as fixed effect, and participant and principle as crossed random effects. Generalized linear mixed-models were conducted with the lme4 (Bates, Maechler, Bolker, \& Walker, 2015) package. Predicted probabilities (notated as $p^{\wedge}$ ) are calculated in the emmeans package in $R$ version 3.6.2. Data and an accompanying $R$ script are available at: https://osf.io/ $\mathrm{hn} 8 \mathrm{~m} 5 /$. 


\section{Results}

\subsection{Preregistered analyses}

Participants in the Actual condition were more likely to report that laws violated procedural principles (Actual: $p^{\wedge}=.54,95 \% \mathrm{CI}_{\text {asymptotic }}[.40, .68]$ ) than participants in the Possible condition were to say that those same principles could be violated (Possible: $p^{\wedge}=.81,95 \%$ $\left.\mathrm{CI}_{\text {asymptotic }}[.72, .89]\right), \mathrm{OR}=3.74,95 \%$ CI [3.41, 4.09], $z=28.43, p<.001$.

Treating country as a fixed factor, we observed a main effect of country, $\chi^{2}(10)=115.0$, condition, $\chi^{2}(1)=823.7$, as well as a country $\times$ condition interaction, $\chi^{2}(10)=169.6$, all $p$ s $<.001$. The country $\times$ condition interaction revealed variation in the magnitude of the effect across cultures, with modest effects emerging in India and the United Kingdom (ORs $<1.60$ ) and large effects in Brazil and Poland (ORs > 7.50). Still, the simple effect of condition was significant in every country when analyzed separately (all $p \mathrm{~s}<.010$ ). Similarly, treating principle as a fixed factor revealed a main effect of principle, $\chi^{2}(7)=1877.4$, and a principle $\times$ condition interaction, $\chi^{2}(7)=598.4$ (while accounting for the effect of condition, $\left.\chi^{2}[1]=710.8\right)$ all $p \mathrm{~s}<.001$. The interaction indicated that the magnitude of the effect varied significantly across principles, going from small for the generality principle $(\mathrm{OR}=1.79)$ to large for the consistency principle $(\mathrm{OR}=13.97$; see also Figure 1). Nonetheless, the simple effect of condition was statistically significant for each of the eight principles individually, all $p$ s $<.001$.

Additionally, our preregistered prediction emerged robustly across age groups and genders, and among lawyers and nonlawyers alike (as detailed in Supplementary Analysis 1). In sum, generalizing the findings of Donelson and Hannikainen (2020), participants in the Possible condition tended to report that laws could not violate various procedural principles even while participants in the Actual condition recognized that they often do.

\subsection{Exploratory analyses}

\subsubsection{Manipulation check}

Modal language is employed primarily to represent necessity and possibility. For instance, the question "Could there be life on Mercury?" concerns a physical possibility, just as the assertion that "There could not be any married bachelors" expresses a logical impossibility. Collectively, these are referred to as alethic modals, insofar as they purport to assess questions of necessity and possibility. In some contexts, however, modal language can also be employed to denote so-called deontic properties-that is, permission and obligation. For instance, the question "Could I sit next to you?" does not, generally speaking, inquire whether the action in question is physically possible. Rather, it requests permission from the listener, asking whether the action (i.e., sitting next to the listener) is allowed or forbidden, desirable or undesirable, from the perspective of the listener.

Though these varieties of modality are easily distinguished in thought, natural languages tend to offer imperfect ways of doing so-raising the possibility that participants interpreted the statements in our experiment as deontic rather than alethic modals. 
Table 3

Task interpretation: marginal means by condition

\begin{tabular}{|c|c|c|c|c|c|c|}
\hline & \multicolumn{2}{|c|}{ Marginal means $[95 \% \mathrm{CI}]$} & \multicolumn{2}{|c|}{$\begin{array}{l}\text { Fixed effect } \\
\text { (condition) }\end{array}$} & \multicolumn{2}{|c|}{$\begin{array}{l}\text { Random effects } \\
\text { (country) }\end{array}$} \\
\hline & Actual & Possible & $z$ & $p$ & (int.) & (slope) \\
\hline Alethic & $\begin{array}{l}1.01 \\
\quad[0.73,1.29]\end{array}$ & $\begin{array}{c}1.44[1.23, \\
1.64]\end{array}$ & 3.38 & .008 & 0.39 & 0.37 \\
\hline Deontic & $\begin{array}{l}0.71 \\
\quad[0.33,1.10]\end{array}$ & $\begin{array}{c}1.24[1.03, \\
1.45]\end{array}$ & 3.61 & .006 & 0.55 & 0.43 \\
\hline Empirical & $\begin{array}{l}1.24 \\
{[1.05,1.43]}\end{array}$ & $\begin{array}{c}0.68[0.32, \\
1.04]\end{array}$ & -3.96 & .003 & 0.25 & 0.43 \\
\hline
\end{tabular}

Table 4

Correlation between interpretation measures in the Actual (below diagonal) and Possible (above diagonal) conditions

\begin{tabular}{lllll}
\hline & & $(1)$ & $(2)$ & $(3)$ \\
\hline$(1)$ & Alethic & - & $.35^{* * *}$ & $.48^{* * *}$ \\
& & & {$[.31, .40]$} & {$[.44, .52]$} \\
$(2)$ & Deontic & $.48^{* * *}$ & - & $.15^{* * *}$ \\
& & {$[.44, .52]$} & & {$[.09, .20]$} \\
$(3)$ & Empirical & .03 & .01 & - \\
& & {$[-.02, .09]$} & {$[-.05, .06]$} & \\
\hline
\end{tabular}

$* * * \mathrm{p}<.001$

To examine this possibility, we probed participants' interpretations of the task through a set of three post-test questions. In mixed-effects linear regression models with country as a random effect, we examined the effect of condition on each interpretation measure (see Table 3). As expected, participants viewed the existential construction ("There are laws...") as inviting an empirical assessment about "what laws are usually like in [their] experience" $(z=-3.96, p=.003)$. Meanwhile, the modal construction ("There could be laws...") was interpreted as describing both what laws "must be like in order to count as law" (an alethic interpretation; $z=3.38, p=.008$ ) and what laws "should be like ideally, according to [one's] beliefs about right and wrong" (a deontic interpretation; $z=3.61, p=.006$ ).

\subsubsection{Effects of task interpretation}

The measures of participants' interpretation of the task were moderately correlated in each condition (see Table 4). As such, estimating the impact of task interpretation via moderation analyses could be jeopardized by the presence of multicollinearity (but see Supplementary Analysis 3). Instead, to examine whether our primary finding depended on participants' interpretation of the task (and, particularly, of the modal construction in the Possible condition), we conducted latent profile analyses (Collins \& Lanza, 2009) identifying patterns of interpretation (or latent profiles) across the three items in each condition. 
These person-centered analyses revealed that differences in task interpretation were driven by a minority profile in each condition: In the Actual condition, one-in-five $(n=352)$ participants reported reflecting on the empirical facts about law $\left(M_{\text {empirical }}=1.59,95 \%\right.$ CI $[1.43$, $1.74], \mathrm{SD}=1.50)$, but not its necessary $\left(M_{\text {alethic }}=-0.32,95 \% \mathrm{CI}[-0.53,-0.12], \mathrm{SD}=1.98\right)$ or deontic $\left(M_{\text {deontic }}=-2.07,95 \%\right.$ CI $\left.[-2.16,-1.97], \mathrm{SD}=0.92\right)$ properties. Meanwhile, the majority reported a fairly indiscriminate, hybrid interpretation $(1.19<$ all $M \mathrm{~s}<1.47,1.14<$ all $S D$ s $<1.42)$. Similarly, a minority in the Possible condition $(n=237)$ reported focusing on the necessary properties of law $\left(M_{\text {alethic }}=0.56,95 \%\right.$ CI $[0.22,0.67], \mathrm{SD}=2.07 ; M_{\text {empirical }}=$ $0.30,95 \% \mathrm{CI}[-0.06,0.37], \mathrm{SD}=1.97)$, but not its deontic properties $\left(M_{\text {deontic }}=-1.84,95 \%\right.$ $\mathrm{CI}[-1.97,-1.71], \mathrm{SD}=1.02)$-while again a large majority reported a hybrid interpretation $(0.82<$ all $M \mathrm{~s}<1.79,1.05<$ all $S D \mathrm{~s}<1.58)$.

Still, our primary prediction (concerning the effect of condition on endorsement) was borne out even among participants in the minority profiles-who reported a selective interpretation (Actual: $p^{\wedge}=.50,95 \% \mathrm{CI}_{\text {asymptotic }}[.36, .64]$; Possible: $p^{\wedge}=.78,95 \% \mathrm{CI}_{\text {asymptotic }}[.65, .86]$ ), $\mathrm{OR}=3.46, z=11.65, p<.001$. This result rules out one particular explanation for the primary finding: namely, that participants interpreted the modal in a deontic manner, asking themselves whether laws should observe the procedural principles in question (or be allowed to violate them); and therefore that the difference between conditions reflects the recognition that laws occasionally violate certain principles that ideally they ought to observe.

\section{Discussion}

Countries and jurisdictions differ substantially in the extent to which their legal systems observe fundamental principles of the rule of law (World Justice Project, 2020). One might expect that this variation would lead to cultural differences in people's concept of law. Yet, our present findings suggest that there is a remarkable level of agreement about the procedural constraints on law-observable throughout the adult life span, across highly dissimilar cultures and languages, and in lawyers and laypeople alike. People consistently believe that laws necessarily abide by a series of procedural principles: they could not retroactively punish past conduct, be kept secret, or be incomprehensible to most, for instance. Yet, people also acknowledge that laws in practice violate these very principles.

The legal systems of the 11 countries in the study vary in large and significant ways; the sample includes civil law and common law systems, countries with varying degrees of religious influence on their laws, and countries with diverse political, representational, and legislative systems. These features are obviously relevant to other important legal and political questions, but it is noteworthy that laypeople - across all of these different legal systemsshare common intuitions about the concept of law.

Although our study provided clear evidence of the phenomenon in question, it afforded limited insight into the psychological processes that engender conflicting beliefs about actual versus possible laws.

A growing body of evidence demonstrates mutual influences between descriptive and prescriptive reasoning: Descriptive considerations—such as whether a behavior is common or 
rare-can sometimes be vested with normative weight, for example, when people punish nonconformity to group norms (Roberts, Gelman, \& Ho, 2017; Roberts, Ho, \& Gelman, 2019). Similarly, prescriptive considerations-such as whether a particular conduct is morally good or evil-can shape descriptive judgments, for example, about whether such conduct is even possible (Goldring \& Heiphetz, 2020; Phillips \& Cushman, 2017).

Our present findings could be understood as a manifestation of the latter phenomenon: When prompted to reason about whether laws necessarily exhibit certain procedural constraints, most participants also considered whether such constraints would be desirable or undesirable. And yet, in both person-centered and variable-centered analyses (see Supplementary Analysis 3), even those who interpreted the modals in a purely alethic fashion demonstrated a comparable effect. As such, our study provided at least some negative evidence concerning the mechanism: that is, that the effect is not driven by the ambiguity that pervades modality in natural languages.

Since we assessed participants' engagement in prescriptive thinking through their explicit reports, this still leaves open unconscious pathways from prescriptive considerations to judgments of necessity and possibility. In previous research, the tendency to interpret immoral states of affairs as impossible arose mostly strongly in conditions favoring a quick and intuitive assessment (i.e., under time pressure, see Phillips \& Cushman, 2017). Therefore, future work could investigate whether a broader, intuitive association between immorality and impossibility undergirds people's endorsement of procedural constraints on law.

A long tradition of research on essentialist thinking has demonstrated that people infer category membership - for instance, whether something is a tiger (Gelman \& Wellman, 1991), or a work of art (Liao, Meskin, \& Knobe, 2020)—on the basis of abstract, and even unobservable, qualities which constitute its essence (Gelman, 2004; Keil, 1989). This tendency toward essentialization has also been observed in the legal context, when explaining stigma surrounding criminals (i.e., as criminality is attributed to an intrinsic property of criminals; see Dunlea \& Heiphetz, 2020). Our present results can also be seen in this light: that is, as revealing the qualities that people consider the essence of law, and which readily come to mind when considering prototypical category members.

Relatedly, recent work reveals that various abstract concepts, such as love, friendship, or art (Del Pinal \& Reuter, 2017; Knobe, Prasada, \& Newman, 2013; Liao et al., 2020), also demonstrate certain trademarks of essentialist thinking: Building on the notion of dual character concepts, these studies demonstrate that being a true friend or a true artist depends on the instantiation of deeper criteria for category membership, even when the superficial criteria may be absent (Newman \& Knobe, 2019; Rose \& Nichols, 2020). This body of evidence points toward a promising avenue for further research: Potentially, by comparison to empirical reasoning about actual laws, modal reasoning about possible laws draws attention toward deeper criteria for category membership (i.e., could true laws lack these procedural properties?), such as the purpose of laws (Rose \& Nichols, 2020; Struchiner, Hannikainen, \& de Almeida, 2020) or their moral dimension (Flanagan \& Hannikainen, 2020; Knobe et al., 2013).

Finally, we must note that the magnitude of the effect varied substantially across countries, which may imply some degree of cultural variability. Relatedly, our sampling methods 
differed substantially across sites; so variation in the magnitude of the effect might also reflect differences in sample composition, attentiveness, or even acquiescence (see Heine, Lehman, Peng, \& Greenholtz, 2002).

Cognitive science has made ample progress in drawing the contours of the moral (Cushman et al., 2006; Graham et al., 2009) and economic (Boyer \& Pedersen, 2018; Henrich et al., 2005) mind - while comparatively neglecting to investigate the psychological and cultural bases of legal concepts. The present work represents an early step in this research program, and provides evidence of cross-cultural convergence in people's understanding of the nature of law. We reveal a striking degree of universality in beliefs about the essential properties of law, despite abundant historical and regional variation in the way actual laws manifest.

\section{Author contributions}

IRH and RD conceived the study concept. IRH, KPT, GA, VD, MK, and NS developed and designed the study. All authors were involved in data collection and stimuli development. IRH wrote the first draft with substantial contributions from KPT. All authors provided critical revisions and approved the final version of the manuscript for submission.

\section{Open Research Badges}

\section{all}

This article has earned Open Data and Open Materials badges. Data and materials are available at https://osf.io/sk2z4/ and https://osf.io/vrp85/.

\section{References}

Awad, E., Dsouza, S., Shariff, A., Rahwan, I., \& Bonnefon, J. F. (2020). Universals and variations in moral decisions made in 42 countries by 70,000 participants. Proceedings of the National Academy of Sciences, 117(5), 2332-2337.

Barrett, H. C., Bolyanatz, A., Crittenden, A. N., Fessler, D. M., Fitzpatrick, S., Gurven, M., ... Laurence, S. (2016). Small-scale societies exhibit fundamental variation in the role of intentions in moral judgment. Proceedings of the National Academy of Sciences, 113(17), 4688-4693.

Bates, D., Maechler, M., Bolker, B., \& Walker, S. (2015). Fitting linear mixed-effects models using lme4. Journal of Statistical Software, 67(1), 1-48.

Boyer, P., \& Petersen, M. B. (2018). Folk-economic beliefs: An evolutionary cognitive model. Behavioral and Brain Sciences, 41, e158. https://doi.org/10.1017/S0140525X17001960

Brown, D. E. (1991). Human universals. Mc-Graw Hill.

Collins, L. M., \& Lanza, S. T. (2009). Latent class and latent transition analysis: With applications in the social, behavioral, and health sciences (Vol. 718). John Wiley \& Sons.

Cushman, F., Young, L., \& Hauser, M. (2006). The role of conscious reasoning and intuition in moral judgment: Testing three principles of harm. Psychological Science, 17(12), 1082-1089.

Dainow, J. (1966). The civil law and the common law: Some points of comparison. American Journal of Comparative Law, 15, 419. 
Del Pinal, G., \& Reuter, K. (2017). Dual character concepts in social cognition: Commitments and the normative dimension of conceptual representation. Cognitive Science, 41, 477-501.

Donelson, R., \& Hannikainen, I. R. (2020). The inner morality of law revisited. In T. Lombrozo J. Knobe \& S. Nichols (Eds.), Oxford Studies in Experimental Philosophy. (Vol. 3, pp. 6-28). Oxford University Press.

Dunlea, J. P., \& Heiphetz, L. (2020). Children's and adults' understanding of punishment and the criminal justice system. Journal of Experimental Social Psychology, 87, 103913.

Finnis, J. (1980). Natural law and natural rights. Oxford University Press.

Flanagan B., Hannikainen I. R. (2020). The Folk Concept of Law: Law Is Intrinsically Moral. Australasian Journal of Philosophy, 1-15. https://doi.org/10.1080/00048402.2020.1833953.

Fuller, L. L. (1964). The morality of law (Vol. 21). New Haven, CT: Yale University Press.

Gelman, S. A. (2004). Psychological essentialism in children. Trends in Cognitive Sciences, 8(9), 404-409.

Gelman, S. A., \& Wellman, H. M. (1991). Insides and essences: Early understandings of the non-obvious. Cognition, 38, 213-244.

Goldring, M. R., \& Heiphetz, L. (2020). Sensitivity to ingroup and outgroup norms in the association between commonality and morality. Journal of Experimental Social Psychology, 91, 104025.

Graham, J., Haidt, J., \& Nosek, B. A. (2009). Liberals and conservatives rely on different sets of moral foundations. Journal of Personality and Social Psychology, 96(5), 1029.

Haidt, J., Koller, S. H., \& Dias, M. G. (1993). Affect, culture, and morality, or is it wrong to eat your dog? Journal of Personality and Social Psychology, 65(4), 613.

Hannikainen, I. R., Machery, E., Rose, D., Stich, S., Olivola, C. Y., Sousa, P., ... Zhu, J. (2019). For whom does determinism undermine moral responsibility? Surveying the conditions for free will across cultures. Frontiers in Psychology, 10, 2428.

Heine, S. J., Lehman, D. R., Peng, K., \& Greenholtz, J. (2002). What's wrong with cross-cultural comparisons of subjective Likert scales?: The reference-group effect. Journal of Personality and Social Psychology, 82, 903-918.

Henrich, J., Boyd, R., Bowles, S., Camerer, C., Fehr, E., Gintis, H., ... Tracer, D. (2005). "Economic man” in cross-cultural perspective: Behavioral experiments in 15 small-scale societies. Behavioral and Brain Sciences, 28(6), 795-815.

Hoebel, E. A. (1954). The law of primitive man: A study in comparative legal dynamics. Cambridge, MA: Harvard University Press.

Keil, F. C. (1989). Concepts, kinds, and cognitive development. Cambridge, MA: MIT Press.

Knobe, J., Prasada, S., \& Newman, G. E. (2013). Dual character concepts and the normative dimension of conceptual representation. Cognition, 127(2), 242-257.

Liao, S. Y., Meskin, A., \& Knobe, J. (2020). Dual character art concepts. Pacific Philosophical Quarterly, 101(1), $102-128$.

Margolis, E., \& Laurence, S. (Eds.). (1999). Concepts: Core readings. MIT Press.

Merryman, J. H., \& Pérez-Perdomo, R. (2020). The civil law tradition: An introduction to the legal systems of Europe and Latin America (4th ed.). Stanford University Press.

Mikhail, J. (2007). Universal moral grammar: Theory, evidence and the future. Trends in Cognitive Sciences, 11(4), 143-152.

Mikhail, J. (2009). Is the prohibition of homicide universal? Evidence from comparative criminal law. Brooklyn Law Review, 75, 497.

Nader, L. (1965). The anthropological study of law 1. American Anthropologist, 67(6), 3-32.

Newman, G. E., \& Knobe, J. (2019). The essence of essentialism. Mind \& Language, 34(5), 585-605.

Ofosu, E. K., Chambers, M. K., Chen, J. M., \& Hehman, E. (2019). Same-sex marriage legalization associated with reduced implicit and explicit antigay bias. Proceedings of the National Academy of Sciences, 116(18), 8846-8851.

Phillips, J., \& Cushman, F. (2017). Morality constrains the default representation of what is possible. Proceedings of the National Academy of Sciences, 114(18), 4649-4654.

Roberts, S. O., Gelman, S. A., \& Ho, A. K. (2017). So it is, so it shall be: Group regularities license children's prescriptive judgments. Cognitive Science, 41, 576-600. 
Roberts, S. O., Ho, A. K., \& Gelman, S. A. (2019). The role of group norms in evaluating uncommon and negative behaviors. Journal of Experimental Psychology: General, 148(2), 374.

Rose, D., \& Nichols, S. (2020). Teleological essentialism: Generalized. Cognitive Science, 44(3), e12818.

Rozin, P., Lowery, L., Imada, S., \& Haidt, J. (1999). The CAD triad hypothesis: A mapping between three moral emotions (contempt, anger, disgust) and three moral codes (community, autonomy, divinity). Journal of Personality and Social Psychology, 76(4), 574.

Struchiner, N., Hannikainen, I. R., \& de Almeida, G. F. C. F. (2020). An experimental guide to vehicles in the park. Judgment and Decision Making, 15(3), 312-329.

Sznycer, D., \& Patrick, C. (2020). The origins of criminal law. Nature Human Behaviour, 4(5), 506-516.

Thalmayer, A. G., Toscanelli, C., \& Arnett, J. J. (2021). The neglected 95\% revisited: Is American psychology becoming less American? American Psychologist, 76(1), 116-129.

World Justice Project. (2020). Rule of Law Index 2020. https://worldjusticeproject.org/sites/default/files/ documents/WJP-ROLI-2020-Online_0.pdf

\section{Supporting Information}

Additional supporting information may be found online in the Supporting Information section at the end of the article.

Supporting information

Supporting information 